Our Nature (2007)5:37-40

\title{
New Report on the Symbiotic Relation of Ochotona roylei (Lagomorpha: Ochotonidae) and Scaly Breasted Wren Babbler (Pnoepyge albiventer) at Ganesh Himalaya Area of Central Nepal
}

\author{
Bhaiya Khanal \\ Natural History Museum, Swayambu, Kathmandu,Nepal \\ Email:baya2000@hotmail.com
}

Received: 19. 11.2007, Accepted: 12.12.2007

\begin{abstract}
The symbiotic relationship of bird and pika is still a least understood phenomenon in biological science. This study at $3300 \mathrm{~m}$ near Somdang of Ganesh Himal area of central Nepal provided a new and interesting information on the behavior of Royle's Pika (Ochotona roylei) which shared its haypile with a bird called Scaly Breasted Wren Babbler (Pnoepyge albiventer). Among the inspected 11 haypiles one haypile was observed sheltering both bird and pika.
\end{abstract}

Keywords: Symbiotic, behavior, haypiles, pika, relationship

\section{Introduction}

Pikas are unpopular small lagomorphs having rounded ears, short legs and devoid of tails. They have little longer front legs than the rear ones. These animals are absolutely restricted to the Himalayas, the mountains and steppes of central Asia, and the mountains of western North America (Prater, 1965). The presence of four incisors differentiates it from rodent which bears two incisors only. Altogether five species of this mammal has been reported in Nepal Himalaya out of 29 species worldwide (IUCN, 1990). The fairly common species in Nepal is Ochotona roylei which is distributed along the northern highland belts of Nepal.

The talus dwelling pikas have low and constant densities as compared to the burrowing pikas found in the Himalayan moss forests (Smith et al., 1990). Various evidences have shown a good relation of livestock to pika's haypiles. Melnikov (1974) has stated that the domestic cows and horses generally locate Pika's haypiles and start feeding the hays deposited in there. This generally happens in winter when the pasture land is covered with snow. According to Naumov (1974), shrews (Sorex sp.) which are insectivorous in their diet generally hunt Pika's haypiles in alpine region to feed upon insects present in there. Around Pika's caches the voles and shrews are more numerous almost to five times more than in the surrounding areas.

\section{Diversity of Symbiotic Animals}

Pika burrows are interestingly shared with other faunal components mainly small mammals and birds. In Tibetan Plateau, the burrows of the Plateau Pika offer breeding habitat for many bird species like Hume's Ground Jay (Pseudopodoces humilis) and 
Bhaiya Khanal / Our Nature (2007)5: 37-40

several species of snow finches (Meyer de Schaunensee 1984, Ma 1995, Schaller 1998, Smith et al., 1990). According to Smith et al. (1996), Pere David's Snow Finch (Pyrgiauda davidiana) and Isabelline wheatear (Oenanthe isabelfina) regularly nest in the holes of Daurian pikas. The native lizards (Phrynocephalus, Eremias) in Tibet also use pika's burrows as breeding sites. The burrows of Afghan pikas are shared with rock dwelling Persian jird Meriones persicus, Libyan jird $M$. libycis, great gerbil Rhombomys opimus, mouse like hamster Calomyscus mystax, gray hamster Cricetulus migratorius and White toothed Shrews Crocidura spp. (Sapargeldyev,1987). Various studies made in Mongolia have shown that the ground squirrels Spermophilus undulates and Hamsters and voles, live in the burrows of Pallas's Pika $O$. pallasi pricei (Smith et al., 1990). The caches or burrows of Black Lipped Pika provide nesting habitats for several species of birds at the Tibetan plateau:

\section{Methodology}

This study was made in the remote Ganesh Himalaya area of northern Kathmandu in April of 1993. About 11 haypiles of pikas were studied for bird-pika mutual relationships. One haypile at an elevation of $3300 \mathrm{~m}$ provided very good result and was studied in greater details. Mr. Hari Sharan Kazi, the well known ornithologist, who was also present in this study, was quite helpful to identify the bird species (Scaly breasted Wren Babbler) observed in pika's haypile.

Direct observation was made on pika and bird relationship. Displayed behavior at each sighting was noted down. This study was continued for two days and is the first ever report on Royle's Pika and Scaly Wren Babbler's symbiotic relation though Pika and Finch's relation was already reported by H.S. Nepal which is mentioned by Fleming (2000).

\section{Results}

\section{Diagnosis of Pika species}

Based on morphological characteristics, the observed species was identified as Royles Pika (Ochotona roylei). This mammal lives in two types of habitat at higher elevations a. moss forest and $\mathbf{b}$. talus environment. The talus dwellers live under rocks and piles of stones while the forest dwellers make burrows under the roots of trees. The vegetable diet of Pika varies considerably with the season still coarse grasses are reported as their major diet. In higher elevation, they also feed upon alpine flowers, berries, leaves etc. Ochotona roylei (Royle's Pika) has a wide range of distribution in the Himalayas though distributional gaps occur in some places. Their altitude ranges from $3400-4300 \mathrm{~m}$.

\section{Diagnosis of Bird species}

According to Mr. H.S Kazi (pers.com.) and Fleming (2000), the Scaly Breasted Wren Babbler (Pnoepyge albiventer) is a common bird which generally occurs at 610 to 3560 $\mathrm{m}$ in the mountains. This bird can be seen at Phulchoki and Sheopuri mountains of Kathmandu as well. The distributional range of this bird is also extended to Grahwal, Sikkim, Himalayas to Formosa.

Every observed data in the field was noted down.

\section{Field Observation}

April 23, 1993.

a. Royles Pika (Ochotona roylei) and Scaly Breasted Wren Babbler (Pnoepyge albiventer) showed up together at $9 \mathrm{am}$. The 
Bhaiya Khanal / Our Nature (2007)5: 37-40

bird stayed out very close to pika and both were basking sun; pika was very alert to the calm surrounding. They returned to their haypile after refreshing out for 15 minutes. The bird was searching food on the ground not leaving pika very apart.

b. At $9.45 \mathrm{am}$, both the bird and pika appeared again, the pika looked around very cautiously. This lagomorph approached to feed upon tender petals of Primula plant. The bird was seen picking something on the ground (may be seeds).

c. The next observation was made at 11.30 am when both were out for about 15 minutes. This time, pika accompanied by bird rested upon a boulder and looked around if any predators are present there.

d. The same day, next observation was made at $1 \mathrm{pm}$. Both animals returned to their established shelter staying out for 10 minutes.

April 24, 1993.

The pika and bird appeared actively when sun hit the ground around $8 \mathrm{am}$. We started exploring ten other haypiles which were found occupied by pikas only. These lagomorphs appeared frequently and were observed attentive and alert against slight disturbances around.

We were back again to observe the previous haypile occupied by pika and bird. Like before, coming out of pika and bird continued till $12.30 \mathrm{pm}$ at every interval of 20-30 minutes. The total observation was made for four times. Usually, both stayed outside for a short period. In afternoon, their frequency of showing up declined remarkably.

The co-existence of Royal Pika (Ochotona roylei) and Scaly Breasted Wren
Babbler (Pnoepyge albiventer) was quite interesting and provided a good example of symbiotic relation of animals in nature. Royal Pikas are hypsobiont species which occur both in the talus and forest habitats above $2800 \mathrm{~m}$ of elevation. The forest form is considered more social than the talus one.

\section{Causes of Symbiotic Relationship}

a. The scarcity of suitable nesting sites at higher elevation might have caused babbler to share pika's haypile.

b. Undisturbing nature of the Wren Babbler to Pika's internal life style might be the possible cause of their symbiotic relationship.

c. The narrow cache of Pika if occupied by the bird may impart warmness to the surrounding as higher elevation is very cold and harsh condition prevails here year round. This kind of co-existence can be a better mechanism for heating inner environment.

d. Their non-competent nature for food can be believed for co-existence.

e. This kind of relationship may alert each other in their home range area if any predator approaches to them.

\section{Discussion}

According to Primack (1998), Pika is a keystone species if lost once will disturb proper functioning of an ecosystem. It provides shelter to many small birds, lizards and insects and also helps to increase in plant diversity by disturbing microhabitat condition around the vicinity of the hay pile areas.

Some pollinating fly species often seek shelter in Pika's burrows. Interesting 
Bhaiya Khanal / Our Nature (2007)5: 37-40

examples of bird and Pika association was reported by H.S. Nepali in June 1977 in Red Necked Snow Finch (Montifringilla ruficollis) and Blandford's Snow Finch (Montifringilla blanfordi) at $4819 \mathrm{~m}$ of elevation in north Mustang of Nepal (Fleming et al., 2000). They were observed feeding together near openings of the Pika's burrows.

The catching of food is very weakly developed in Royle's Pika, although they apparently are more likely to construct haypiles than the large eared Pika (Ochotona macrotis) (Kawamichi, 1971a). This species is sympatry to Royale's Pika in Rasuwa district of central Nepal. Shrestha and Khanal (1999) indicated that about 33 species of plants were deposited in the haypiles of this animal and 48 species of plants were observed within the home range of Royle's Pikas. They found plants like Stellaria, grasses and mosses as major depositions in haypiles. This study found that pikas are relatively active in morning sun and were seen crossing snow beds to reach their foraging plants for catching hays. In after noon, they decline their activities and hide themselves in their caches.

\section{Acknowledgements}

Natural History Museum of Nepal is acknowledged for granting my affiliation in this research program. Dr. Jeff Groth, Senior Ornithologist of American Museum of Natural History, New York is appreciated for his kind cooperation to my field research. I owe my special thank to Mr. H. S. Nepali "Kazi' whose cooperation, company and information was highly valuable to me. Dr. Garry Ahlburn is acknowledged for his timely help in the field.

\section{References}

Fleming. R.L. Sr., R.L. Fleming Jr. and L.S. Bangdel. 2000. Birds of Nepal. Adarsh Enterprises, Delhi, India, pp.320-321.

IUCN 1990. Rabbit, hares and pikas: Status, survey and conservation action plan. IUCN, Switzerland, pp.14-60.

Kawamichi, T. 1971a. Daily activities and social pattern of two Himalayan Pikas, Ochotona macrotis and $O$. royle $i$, observed at Mt. Everest. J. Fac.Sci. Hokkaido. Univ. Japan. Ser.VI, Zool, 17: 587-609.

Ma, M. 1995. Suggestions for the protection of some pikas. China Nature 2: 26

Melnikov, V.K. 1974. On the ecology of ochotona alpine pall in the western Sayan Mountains. Byull. Mosk.Obsh. Ispytat. Prirody, Otd. Biol. 79: 141-142.

Meyer de Schauensee, R. 1984. The Birds of China. Smithsonian Institution Press. Washington DC.

Naumov, R.L.. 1974. Ecology of ochotona alpine in the west Sayan. Zool.Zh.53: 1524-1529.

Prater, S.H. 1965. Book of Indian animals. Bombay Natural History Society, Hornbill House Bombay, India pp.218-221

Primack, R.B. 1998. Essentials of conservation biology, $2^{\text {nd }}$ edition. Sinauer, Sunderland, Massachusetts.

Sapargeldyev, M. 1987. Ecology of the Afghan pika in Turkmenistan. Ylym, Ashkhabad.144p.

Schaller, G. 1998. Wildlife of the Tibetan steppe. Chicago, University of Chicago Press.

Shrestha, K., B. Khanal and J.B. Karki, 1999. Foraging and haying plants of Royles Pika (Ochotona roylei: Lagomorpha) in far-west Nepal. Journal of Natural History Museum 18: 3-13.

Smith, A.T. and J. Marc Foggin. 1996. The plateau pika is a keystone species for biodiversity on the Tibetan plateau. In: Conserving China's Biodiversity (II) (Eds. P. Johan Schei, Wang Sung and XIE Yan). China Environmental Science Press, Beijing. pp.211-221.

Smith, A.T., A. N. Formozov, R. S. Hoffmann, Zheng Changlin and M. A. Erbajeva. 1990. The pikas. In: Rabbits, hares, and pikas: Status survey and conservation action plan (Eds. J. A. Chapman and J. E. C. Flux). IUCN, Gland, Switzerland, pp. 14-60. 